\title{
Genetic, farm, and lactation effects on behavior and performance of US Holsteins in automated milking systems
}

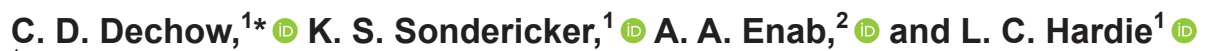 \\ ${ }^{1}$ Department of Animal Science, Pennsylvania State University, University Park, 16802 \\ ${ }^{2}$ Department of Poultry Production, Menoufia University, Shebin El-Kom, Egypt, 32511
}

\begin{abstract}
Selecting for favorable behavior and performance could enhance the efficiency of production in automated milking systems (AMS). The objectives of this study were to describe AMS behavior and performance in Holsteins, estimate genetic parameters among AMS traits, and determine genetic relationships of AMS traits with other routinely recorded traits. The edited data included 1,101,651 individual milking records and 394,636 daily records from 2,531 lactations and 1,714 cows that resided on 3 farms; data were obtained from the Dairy Data Warehouse (Assen, Netherlands) cloud. Traits considered were individual milking and daily totals for milk yield, milking time, milk harvest rate (the ratio of milk yield to milking time), milk flow rate, electrical conductivity, machine kickoffs, incomplete milkings, and blood in milk; the number of milkings per day and 305-d mature-equivalent milk yield (305ME) were also evaluated. Individual milkings were evaluated with mixed models that included fixed effects of week of lactation, lactation group $(1,2, \geq 3)$, hour of day, and farm; random effects included cow within lactation, lactation group by week of lactation, and interactions of farm with date, hour, week of lactation, and yearseason of calving. Daily records were evaluated with 3 -trait animal models that included 305ME and 2 AMS traits with random additive genetic and permanent environment effects. Estimated breeding values were extracted and correlated with yield, conformation, and udder health genetic evaluations. Farm specific robot access policies had notable effects on week of lactation patterns for milk yield and number of milkings. Mature cows had higher milk harvest rates $(2.05 \mathrm{~kg} / \mathrm{min})$ than first-lactation cows $(1.73 \mathrm{~kg} / \mathrm{min})$ with larger differences in early lactation. First-lactation cows were more likely to kick off the machine $(15.04 \%)$ than mature
\end{abstract}

Received May 5, 2020.

Accepted July 13, 2020.

*Corresponding author: cdd1@psu.edu cows $(8.62 \%)$, particularly in early lactation. Heritability estimates were generally lower for behavior traits (0.03 for incomplete milkings and 0.08 for kickoffs) than for milk harvest rate (0.30) and flow rate (0.55). Udder conformation traits did not have favorable genetic correlations with AMS traits, with the exception that longer teats were correlated with fewer kickoffs $(-0.34)$ and incomplete milkings $(-0.49)$; increased milk harvest rate and flow rate were unfavorably associated with genetic merit for udder health. There is genetic variation for milking efficiency and behavioral traits, suggesting genetic selection to enhance efficiency in AMS systems is possible. Genetic associations with udder conformation indicate that selection for udder morphology is unlikely to substantially improve milking efficiency. This calls for more direct selection of traits related to AMS efficiency.

Key words: automated milking system, heritability, udder conformation, behavior

\section{INTRODUCTION}

Automated milking systems (AMS) reduce the need for human involvement in the milking process and are estimated to milk more than 1.2 million cows in 10,000 dairy herds worldwide (Moyes et al., 2014). The most common reasons cited for implementation of AMS include decreased labor intensity, more time available to spend on other activities, more flexibility, not having to milk, and improved social life (Mathijs, 2004). It is generally observed that AMS are less profitable than milking parlor systems because of the larger capital costs associated with AMS installation; it was recently estimated that an economic life of at least 13 years was required for AMS to have a positive net annual economic impact (Salfer et al., 2017). Increasing the amount of milk harvested per day by the AMS increases economic efficiency (Castro et al., 2012; Salfer et al., 2017); however, maintaining udder health can be challenging with AMS (Hovinen and Pyörälä, 2011), and faster and easier milking is associated with poorer udder health (Rupp and Boichard, 1999; Zwald et al., 
2005; Pantoja et al., 2016). Selection to increase the amount of milk harvested from a cow per minute of time in the milking box might increase AMS efficiency, but should not come at the expense of udder health.

Genetic parameters for milk yield using data from AMS have been estimated (Nixon et al., 2009) and the genetic correlation between milk yield in AMS and conventional milking system is high (Mulder et al., 2004). There is also an opportunity to evaluate novel traits because of the large quantities of data recorded by AMS, including number of milkings per day (König et al., 2006; Nixon et al., 2009), milk flow rates (Carlström et al., 2013, 2014; Wethal and Heringstad, 2019), milk harvested per minute in the milking box (Wethal and Heringstad, 2019), incomplete milkings (Carlström et al., 2016; Wethal and Heringstad, 2019) and machine kickoffs (Wethal and Heringstad, 2019). Milking speed observations from AMS systems could be used to replace traditional evaluations from subjective questionnaires (Wethal et al., 2020) or supplement milking speed data from conventional milking systems (Mulder et al., 2004).

The placement of individual teats is stored as Cartesian coordinates by the AMS to more efficiently locate teats in subsequent milkings; measurements derived from the coordinates such as the difference between teats and the distance from the ground to the udder floor have high heritability and strong genetic correlations with visually appraised udder conformation (Carlström et al., 2016; Poppe et al., 2019) and could be used to evaluate udder conformation. Selection for routinely recorded udder health traits has also been suggested as a mechanism to improve AMS milkability, but relationships were not consistent among breeds (Carlström et al., 2016). Thus, relationships of milkability with udder conformation could depend on population baseline udder conformation and genetic parameters may need to be established in a population specific manner to provide beneficial recommendations.

Selection for traits such as how rapidly cows enter and exit the milking box, the amount of time required for the attachment of teat cups, and the frequency of cows kicking off the machine would increase the amount of milk harvested by the AMS in a given time and potentially decrease AMS failure due to cows breaking equipment; improving such behavioral and milkability traits would carry less risk of increased mastitis incidence compared with selection to increase milk flow rates. Although genetic evaluation for performance specifically in AMS systems is appealing, such data are not available through routine milk recording systems such as DHI testing in the United States. Other mechanisms, such as cloud-based data storage, may aid the data collection required to facilitate such evaluation.
The objectives of this study were to use data retrieved from a cloud-based service to describe how AMS behavior and performance change over the course of lactation, estimate genetic parameters for such traits in US Holsteins, and determine genetic relationships of AMS traits with other routinely recorded traits.

\section{MATERIALS AND METHODS}

\section{Data and Editing}

Data from 1 Pennsylvania and 2 New York farms with DeLaval (DeLaval International AB, Tumba, Sweden) AMS were uploaded to the Dairy Data Warehouse (DDW; Assen, Netherlands) from DelPro Farm Manager software (DeLaval International AB, Tumba, Sweden). The number of AMS devices per farm was 2, 8 , and 20. Data recording began from the date of successful client software installation, which occurred from October 2016 to July 2017. Daily data uploads continued through data retrieval in April 2019 for 2 herds; a software error resulted in data availability through March 2018 for the remaining herd.

All 3 farms housed cows in freestalls that fed a TMR and provided concentrates provided to entice cows to the AMS. The target number of cows per AMS device was 60 cows for 2 herds and 55 cows for 1 herd. In 2 herds, a guided-flow system was used, where cows passed through sort gates that either diverted them to the feed bunk or AMS holding pen; cows had free access to the feed bunk in the third herd and had to pass through a sort gate to enter the AMS holding pen. The AMS systems were installed in 2005, 2015, and 2016.

The data included milk yield by quarter, which was summed to total yield per milking (MY); cluster attachment and removal times, which were used to derive total milking time (MT) in minutes; milk harvest rate (HR, $\mathrm{kg} / \mathrm{min}$, calculated as MY/MT); milk flow rate (FR, $\mathrm{kg} / \mathrm{min}$ ), which was the average flow rate across quarters; electrical conductivity $(\mathbf{E C}, \mathrm{mS})$, which was averaged across quarters; a flag indicating the milking unit was kicked off by the cow (KO); a flag indicating that a milking was incomplete (IC); and an indication that there was blood in the milk (BL), which was scored as 0 for milkings with no blood detected for any quarter and 1 for a milking with any amount of blood detected in 1 or more quarters. Teat cups are not applied or removed by the AMS at the same time for each teat and MT reflects the time from application of the first teat cup to removal of the last teat cup; HR is therefore not quarter specific. Flow rates, on the other hand, are recorded by the AMS on a per-quarter basis and reflect milk produced from the time the teat cup is attached until it is removed from one specific teat. 
Cow birth dates, calving dates, sire identification, dam identification, and 305-d mature-equivalent milk yield (305ME) were obtained from Dairy Comp 305 (Valley Ag Software, Tulare, CA) from 1 herd and from PCDart (Dairy Records Management Systems, Raleigh, NC) from 2 herds. The AMS data did not include historical data. Cows from later parities or that calved for the first time before the commencement of data collection represented a selected population relative to peers born at the same time, but that did not survive to the same age. Therefore, historic $305 \mathrm{ME}$ was obtained from all previous lactations of cows still in the herd and for cows that were culled before data collection to mitigate effects of selection bias on genetic parameter estimates (Pollak et al., 1984; Árnason et al., 2012). The 305ME records were largely from lactations that occurred before installation of the AMS on 2 of the farms. The herd providing the majority of records $(56.9 \%)$ did not participate in DHI testing so fat, protein, and SCS were not considered.

The initial data set included 1,735,855 unique milking records from the AMS. There were 1,101,556 records in the final data after removal of those from cows with no first lactation 305ME or AMS records available $(36.2 \%$ of removed records), records before 5 DIM or after 305 DIM (21.4\%), cows that were not Holstein (12.7\%), cows lacking a unique identification number $(12.7 \%)$, cows greater than $10 \mathrm{yr}$ of age at calving (6.1\%), lactations greater than $5(3.3 \%)$, a milking interval of less than 2 or greater than $24 \mathrm{~h}(2.9 \%)$, cows that had fewer than 25 records in a given lactation $(1.8 \%)$, cows that were milked by an AMS device that recorded fewer than 100 milkings on a given date (1.5\%), and cows that calved before $650 \mathrm{~d}$ of age (1.3\%). The final data had $39.9 \%$ of records from lactation 1, 32.5\% from lactation 2, and $27.6 \%$ from lactation 3 and greater.

The first-lactation data restriction was put in place to mitigate selection bias effects and represented older cows whose earlier records were no longer available. The non-Holsteins $(<87.5 \%)$ were Brown Swiss and crossbred animals that were primarily Holstein sired but with dams that contained Jersey or Norwegian Red ancestry. Electronic identification collars were recycled and records were removed if we were not able to confidently assign a record to a unique cow identification number. Devices that recorded fewer than 100 milkings in a day were assumed to have malfunctioned and removal of those records eliminated a left-tailed distribution of milkings per device. The mean (137) and median (145) were different before removal of those records and were nearly identical (146 and 147, respectively) after removal. Cows beyond fifth lactation are not used in US genetic evaluations, so such records were removed from the data. Records from cows older than $10 \mathrm{yr}$ were removed because records from contemporaries born at the same time and that had been culled were more likely to be missing, which could introduce selection bias to the results; cows beyond $10 \mathrm{yr}$ of age would also be expected to be beyond fifth lactation unless they had long calving intervals. The mean, standard deviation, and range for each trait in the final AMS milking data set are presented in Table 1 . The final AMS data included 1,101,556 records from 2,531 lactations of 1,714 cows.

Daily totals (MY, MT, KO, IC, BL) or averages (HR, FR, EC) for each trait were also derived with means, standard deviations, and ranges reported in Table 2. Descriptive statistics for the traits number of milkings per day (NM) and 305ME are also shown. In total, there were 394,636 daily AMS records and 10,153 $305 \mathrm{ME}$ records. There were 4,104 cows with $305 \mathrm{ME}$ and no AMS records; 629 young cows that calved for the first time after Dairy Comp 305 and PCDart records were retrieved had AMS records but no 305ME.

\section{Individual Milking Analysis}

Records of individual milkings were evaluated with the following mixed model in ASReml (Gilmour et al., 2014):

Table 1. Descriptive statistics of 1,101,556 individual milkings summed across quarters, including mean or percentage of affected records, SD, and range ${ }^{1}$

\begin{tabular}{|c|c|c|c|c|c|}
\hline Trait & Definition & Mean $(\%)$ & $\mathrm{SD}$ & Min & Max \\
\hline MT & Milking time (min) from cluster attachment to removal & 7.23 & 2.08 & 1.50 & 48.78 \\
\hline HR & Milk harvest rate $(\mathrm{kg} / \mathrm{min}) ; \mathrm{MY} / \mathrm{MT}$ & 1.93 & 0.61 & 0.00 & 5.08 \\
\hline EC & Electrical conductivity $(\mathrm{mS})$; average across quarters & 4.66 & 0.60 & 0.44 & 8.33 \\
\hline $\mathrm{KO}$ & Unit kicked off $(\%) ; 1=$ kicked off $\geq 1$ time; $0=$ not kicked off & 12.23 & 32.76 & 0.00 & 100.00 \\
\hline IC & Incomplete milking $(\%) ; 1=$ milking incomplete; $0=$ complete & 5.77 & 23.32 & 0.00 & 100.00 \\
\hline
\end{tabular}

${ }^{1} \operatorname{Min}=$ minimum; $\operatorname{Max}=$ maximum. 


$$
\begin{gathered}
y_{i j k l m n o p}=F_{i}+H_{j}+W O L_{k}+L G_{l}+F D_{m}+C o w_{n} \\
\times L_{o}+F_{i} \times W O L_{k}+L G_{l} \times W O L_{k}+F Y S_{p}+\varepsilon_{i j k l m n o p},
\end{gathered}
$$

where $y$ is a single trait detailed in Table $1 ; F$ is farm $(i=1-3) ; H$ is hour of day $(j=1-24)$; WOL is week of lactation $k(k=1-44) ; L G$ is lactation group $(l=1$, 2 , and $\geq 3)$; $F D$ is farm-date $(m=1-1713)$; Cow is the effect of cow $(n=1-1,714) ; L$ is lactation $(o=1-5)$; FYS is farm-year-season of calving ( $p=1$ to 32$)$; and $\varepsilon=$ residual error. The model was developed for MY with main effects of $F, W O L, L G$, and $H$ as fixed effects that were significant $(P<0.05)$. The remaining items were fit as random effects that improved the Bayesian information criterion fit statistic. Once developed, the same model was applied to all traits so that we could easily contrast which factors affected different aspects of performance; nevertheless, the main fixed effects were either significant, or had random interactions with other effects that were significant, for all traits. The PREDICT directive of ASReml was used to derive adjusted means for comparison of farm, stage of lactation, hour of day, and lactation group effects. Treatment of interactions among effects as random was required to provide estimable predicted values because some levels of interaction may have been empty. For example, no first-lactation cows were milked by the AMS in wk 1 and very few by wk 2 ; of those milked in wk 2 , none were milked between 2000 and $0400 \mathrm{~h}$ because they were fetched to the AMS by farm personnel during normal working hours. The first week of lactation was ignored when deriving predicted values because relatively few multiparous cows were introduced to the AMS during wk 1 and its estimate had a relatively large influence when compared with the number of wk 1 records. The binary traits (KO, IC, and $\mathrm{BL}$ ) were evaluated with both the general linear model described above and with a binary logistic regression model that had the same independent effects.

\section{Genetic Analysis}

Genetic parameters among the daily traits listed in Table 2 were estimated with a series of the following 3 -trait animal model in ASReml:

$$
\mathbf{y}=\mathbf{X b}+\mathbf{Z a}+\mathbf{W p}+\mathbf{V f}+\mathbf{e}
$$

where $\mathbf{y}$ is a vector of $305 \mathrm{ME}$ and 2 AMS traits; $\mathbf{b}$ is a vector of fixed effects including FYS and calving age for all traits plus LG $\times$ WOL for traits other than $305 \mathrm{ME}$; $\mathbf{a}$ is a vector of random additive genetic effects; $\mathbf{p}$ is a vector of permanent environmental effects; $\mathbf{f}$ is a vector of random farm-date effects for the 2 AMS traits; $\mathbf{e}$ is the vector of residual effects; and $\mathbf{X}, \mathbf{Z}, \mathbf{W}$, and $\mathbf{V}$ are the design matrices. The variance associated with farm-date was ignored (i.e., not added to the denominator) when deriving heritability and repeatability estimates. Traits that were binary (KO, IC, BL) were evaluated as linear traits in the above model; however, a single-trait threshold model for those traits was also evaluated to report their heritability and repeatability on the underlying scale; calving age was removed from the threshold models for all traits and FYS and LG $\times$ WOL were treated as random for BL to facilitate convergence. Two other traits related to EC were also considered in single-trait models: the ratio of highest individual quarter EC to lowest individual quarter EC and an indicator of whether EC increased by $15 \%$ or more from the previous 3-d rolling average of EC.

The EBV were extracted from ASReml output for 214 bulls with reliability $\geq 25 \%$ for daily MY; the EBV were merged with genomic PTA (gPTA) from national

Table 2. Descriptive statistics for 394,636 daily totals of automatic milking system traits plus 10,153 lactation total milk yield records (305-d mature-equivalent milk) for the genetic evaluation, including mean or percentage of affected records, $\mathrm{SD}$, and range ${ }^{1}$

\begin{tabular}{lrrcc}
\hline Trait $^{2}$ & Mean $(\%)$ & \multicolumn{1}{c}{ SD } & Min & Max \\
\hline MY (kg) & 37.94 & 11.67 & 0.09 & 96.6 \\
MT (m) & 20.43 & 7.11 & 2.73 & 50.00 \\
HR (kg/min) & 1.96 & 0.56 & 0.01 & 5.01 \\
FR (kg/min) & 1.04 & 0.29 & 0.03 & 9.54 \\
NM & 2.82 & 0.84 & 1 & 100 \\
KO $(\%)$ & 23.49 & 42.39 & 0 & 100 \\
IC $(\%)$ & 12.51 & 33.09 & 0 & 100 \\
BL $(\%)$ & 6.01 & 23.76 & 0 & 6.50 \\
EC (mS) & 4.66 & 0.56 & 2.50 & 19,091 \\
305ME $(\mathrm{kg})$ & 11,714 & 1,960 & &
\end{tabular}

${ }^{1}$ Min $=$ minimum; Max $=$ maximum.

${ }^{2} \mathrm{MY}=$ milk yield $\mathrm{MT}=$ milking time; $\mathrm{HR}=$ harvest rate; $\mathrm{FR}=$ flow rate; $\mathrm{NM}=$ number of milkings; $\mathrm{KO}=$ kickoff; $\mathrm{IC}=$ incomplete; $\mathrm{BL}=$ blood; $\mathrm{EC}=$ electrical conductivity; 305ME $=305$-d mature-equivalent milk yield. 
genetic evaluations for yield and fitness traits (Council on Dairy Cattle Breeding; Bowie, MD) and type traits (Holstein Association USA Inc.; Brattleboro, VT). Correlations among EBV for AMS traits and gPTA for nationally evaluated traits were derived using the CORR procedure of SAS (v9.4; SAS Institute Inc., Cary, $\mathrm{NC}$ ) and adjusted by the product of trait accuracies to approximate genetic correlation estimates (Calo et al., 1973). Partial correlations of HR with gPTA after adjustment for FR were derived using the partial statement of the CORR procedure. The partial correlations were not adjusted to genetic correlations because the trait accuracies were not reflective of adjusted genetic merit.

\section{RESULTS AND DISCUSSION}

\section{Individual Milkings}

Descriptive statistics for the individual AMS milking traits are reported in Table 1 . The average visit to the AMS yielded $13.49 \mathrm{~kg}$ of milk in $7.23 \mathrm{~min}$ for a $\mathrm{HR}$ of $1.93 \mathrm{~kg} / \mathrm{min}$. The range of milk yield was 0.05 to 44.13 $\mathrm{kg}$ per milking. We elected not to remove low milk yield records from the data because they appeared to represent real and nonproductive visits to the AMS. Of the 123 instances with milk yield less than $0.5 \mathrm{~kg}$, a majority (68) were associated with a $\mathrm{KO}$ and 114 were IC; such nonproductive visits compromise AMS efficiency, and we wanted those visits captured in the data.

Our MT is similar to box time estimates of 7.19 to $7.84 \mathrm{~min}$ (Carlström et al., 2013) and $7.46 \mathrm{~min}$ (Wethal and Heringstad, 2019). Box time measures the time from entry into the milking unit through exit from the milking unit, whereas MT was the time from milking cluster attachment through milking cluster removal. Box time is a more complete indicator of milking efficiency (Carlström et al., 2013) as behavioral differences inherent to entry and exit from the milking station are not captured by MT. Box entry and exit times were not captured in our data so we could not determine box time; these measures are collected by AMS software. Closer collaboration of cloud-based services such as DDW and research personnel will be required to generate ideal data to facilitate genetic evaluation.

The MT can be partitioned into a theoretical minimum milking time by determining the time required to milk the slowest quarter with handling time reflecting the difference between box time and minimum milk time. Our theoretical minimum MT was $4.2 \mathrm{~min}$ and handling time was $3.0 \mathrm{~min}$; this handling time is intermediate to previous estimates of 2.6 (Carlström et al., 2016) to $3.1 \mathrm{~min}$ (Wethal and Heringstad, 2019), which suggests that we captured a large proportion of total handling time. Our HR is similar to the ratio of milk yield to box time observed for second and third lactation Swedish Holsteins $(1.98 \mathrm{~kg} / \mathrm{min}$; Carlström et al., 2013), but is not a direct comparison because we do not have box time. We derived FR as an average across quarters, but a total FR can also be derived as the ratio of MY summed across quarters to the theoretical minimum MT. Using that method, our FR (3.38 kg/min) is intermediate to that of previous estimates (Carlström et al., 2013; Wethal and Heringstad, 2019) and is highly correlated (0.93; not shown) to the average FR across quarters presented in Table 1.

Lactation group had a significant effect $(P<0.05)$ for all traits except IC with predicted means by lactation group reported in Table 3. There was an increase in MY, HR, MT, FR, and EC from first to later lactations. If we consider HR as the primary indicator of AMS efficiency, mature cows ( $\geq$ third lactation) were $18.5 \%$ more efficient than their first-lactation counterparts due to a $31.2 \%$ higher yield per milking and a smaller (10.0\%) relative increase in MT. This corresponds to previous observations in Swedish Holsteins where the relative increase in yield per milking was higher than the relative increase in box time for multiparous cows (Carlström et al., 2013). Figure 1 demonstrates that the difference in HR among lactation groups declined as lactation progressed because MY and FR increased in first lactation relative to mature cows, whereas MT decreased after wk 7 in first lactation (Supplemental Figures S1-S3, https://doi.org/10.3168/jds.2020-18786). Some of the increased efficiency of mature cows could be attributed to fewer milkings interrupted by a $\mathrm{KO}(8.62 \%$ vs. $15.04 \%$ ). First parity cows had higher KO, particularly in early lactation (Figure 2). First-lactation cows had numerically higher IC than mature cows, but the effect was not significant. There was an interaction between IC and week of lactation with more IC for first lactation in early lactation (Supplemental Figure S4, https: //doi.org/10.3168/jds.2020-18786). When evaluated with the binary logistic regression model, the lactation group effect did trend toward significance $(P=0.062)$ for IC; however, retransformed predicted values from logistic regression $(3.8 \pm 0.2 \%, 3.5 \pm 0.2 \%$, and $3.1 \pm$ $0.2 \%$ for first, second and mature cows, respectively) were much lower than observed frequencies. We chose to present linear model predicted values. Retransformed predicted values for $\mathrm{KO}$ and $\mathrm{BL}$ were also lower than observed frequencies.

The average EC reported in Table 1 and $2(4.66 \mathrm{mS})$ was similar to a previous report for healthy quarters (Hovinen et al., 2006) and increased (Table 3) from first (4.54) to third and greater lactation (4.76). This could indicate elevated risk of mastitis for older cows as a rise in the probability of mastitis when EC in- 
Table 3. Predicted means of individual milking for lactations 1,2 , and $\geq 3$

\begin{tabular}{|c|c|c|c|c|}
\hline Trait $^{1}$ & 1 & 2 & $\geq 3$ & $P>\mathrm{F}$ \\
\hline MY (kg) & $11.60 \pm 0.21$ & $14.39 \pm 0.21$ & $15.22 \pm 0.22$ & $<0.001$ \\
\hline MT (m) & $6.95 \pm 0.08$ & $7.27 \pm 0.08$ & $7.65 \pm 0.09$ & $<0.001$ \\
\hline $\mathrm{HR}(\mathrm{kg} / \mathrm{min})$ & $1.73 \pm 0.02$ & $2.04 \pm 0.02$ & $2.05 \pm 0.02$ & $<0.001$ \\
\hline $\mathrm{FR}(\mathrm{kg} / \mathrm{min})$ & $0.97 \pm 0.01$ & $1.09 \pm 0.01$ & $1.07 \pm 0.01$ & $<0.001$ \\
\hline $\mathrm{EC}(\mathrm{mS})$ & $4.54 \pm 0.02$ & $4.72 \pm 0.02$ & $4.76 \pm 0.02$ & $<0.001$ \\
\hline KO (\%) & $15.04 \pm 0.01$ & $10.85 \pm 0.01$ & $8.62 \pm 0.01$ & $<0.001$ \\
\hline $\mathrm{IC}(\%)$ & $6.94 \pm 0.01$ & $6.45 \pm 0.01$ & $5.62 \pm 0.01$ & 0.066 \\
\hline BL (\%) & $6.83 \pm 0.01$ & $3.65 \pm 0.01$ & $3.79 \pm 0.01$ & $<0.001$ \\
\hline
\end{tabular}

${ }^{1} \mathrm{MY}=$ milk yield; $\mathrm{MT}=$ milking time; $\mathrm{HR}=$ harvest rate; $\mathrm{FR}=$ flow rate; $\mathrm{EC}=$ electrical conductivity $\mathrm{KO}$

$=$ kickoff; $\mathrm{IC}=$ incomplete; $\mathrm{BL}=$ blood.

creased beyond $5 \mathrm{mS}$ in forestrip milk samples has been reported; the relationship was not apparent in milk collected after forestripping (Khatun et al., 2019). The percentage of milk samples flagged for BL was highest for first lactation $(6.83 \%)$ and lowest for second lactation $(3.65 \%)$. Although BL has been developed as a potential indicator of mastitis, yellow color associated with higher milk fat can cause false positives (Hovinen and Pyörälä, 2011). Khatun et al. (2018) reported no relationship between $\mathrm{BL}$ and clinical mastitis and it seems unlikely the higher BL in first lactation is due to increased mastitis risk as much as somewhat higher milk fat concentration (Miglior et al., 2007) and mammary gland development that extends further into lactation (Safayi et al., 2010) during first parity.

Figure 3 demonstrates predicted MY by week of lactation and farm. For farms 2 and 3, MY increases from calving through approximately the fifth week of lactation at which point it is stable through wk 20 and marginally declines thereafter. Farm 1 has a holding area policy change at 120 DIM, which influences MY. Prior to 120 DIM cows are allowed to enter the holding area and thus access the milking device irrespective of the number cows in the holding area; later lactation cows are only allowed to enter when the holding area is not full, resulting in a jump in yield per milking after $17 \mathrm{wk}$. This corresponds in a decrease in the number of predicted milkings per day from 3.08 at wk 17 to 2.60 at wk 20 (Supplemental Figure S5, https://doi.org/10 $.3168 /$ jds.2020-18786). The effects of guided-flow versus free-flow traffic patterns may also be apparent in Figure S5. Farm 3 cows are not required to go through sort gates to gain access to the feed bunk and had fewer visits to the AMS, particularly in early lactation. Free-traffic systems are associated with reduced milking frequency in many, but not all, studies (Rodenburg, 2017). Predicted MY on an individual milking basis was higher for farm 3 in accordance with fewer visits

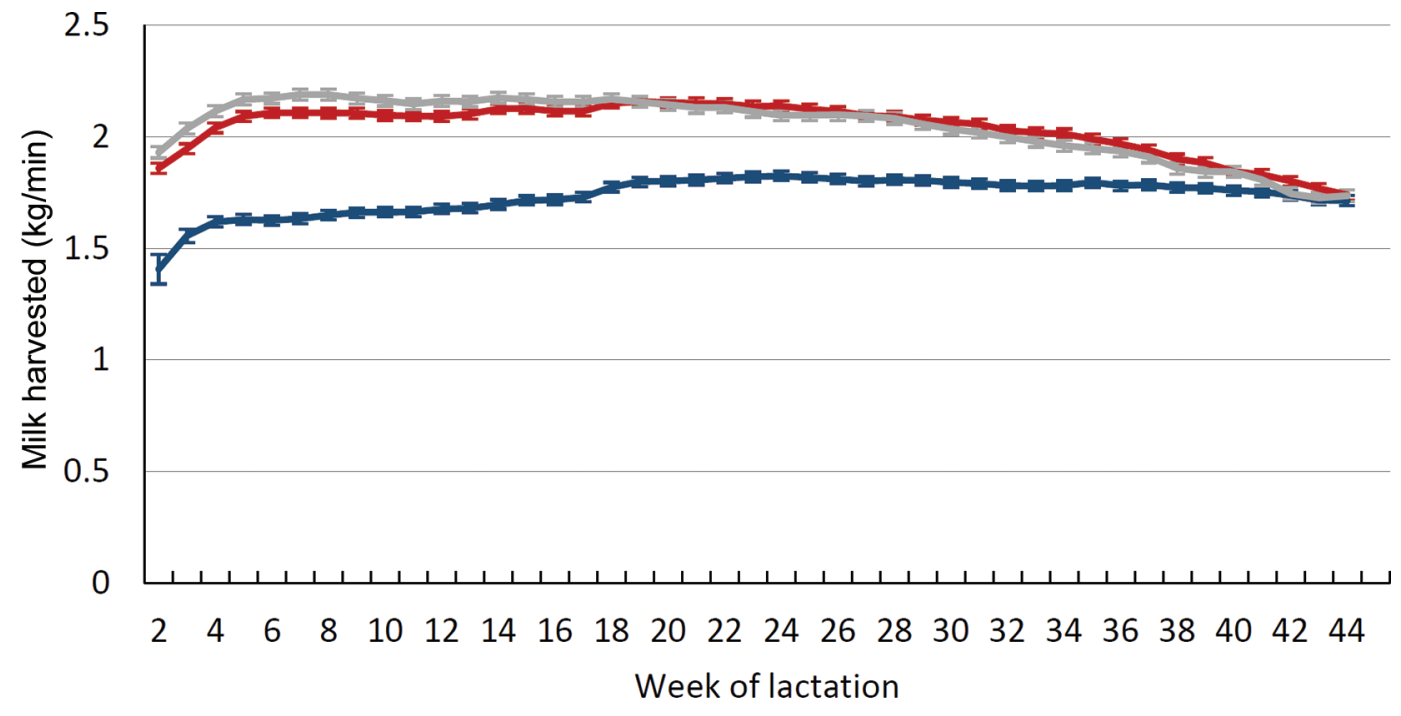

$\longrightarrow$ - $2 \longrightarrow 3$

Figure 1. Milk harvested per minute $( \pm \mathrm{SE})$ by lactation group $(1,2$, or $\geq 3)$ and week of lactation. 


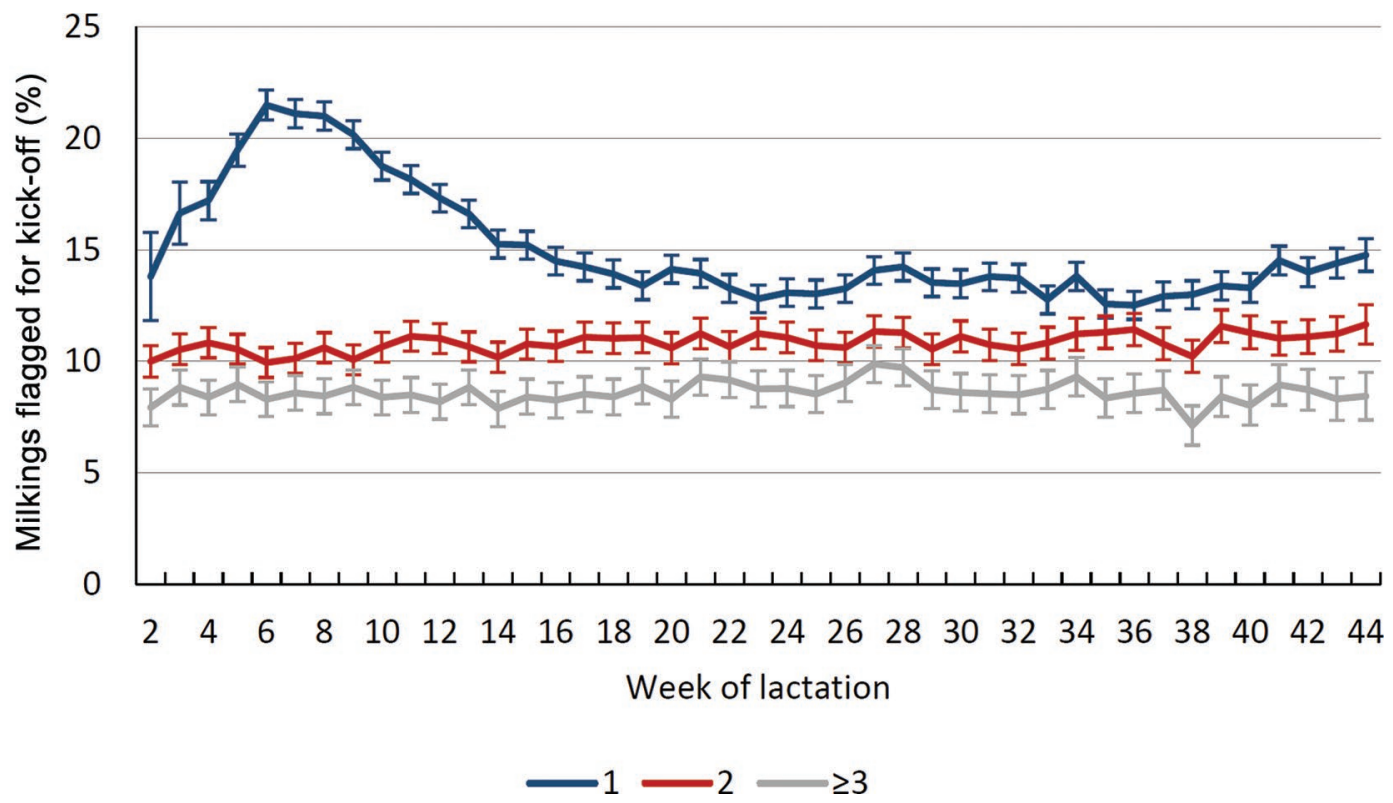

Figure 2. Percent $( \pm \mathrm{SE})$ of milkings with the machine kicked off by lactation group $(1,2$, or $\geq 3)$ and week of lactation.

to the AMS in early lactation. Across lactation, farm 3 had total daily MY (37.1 $\mathrm{kg}$ unadjusted mean) that was between farm $1(39.3 \mathrm{~kg} / \mathrm{d})$ and farm $2(35.4 \mathrm{~kg} / \mathrm{d})$.

Although the lactation curve is relatively flat when viewed on a per milking basis as in Figure 3, total daily MY is a function of yield per milking plus the number of milkings per day. Lactation curves for total daily MY by lactation group are demonstrated in Supplemental Figure S6 (https://doi.org/10.3168/jds.2020-18786), which shows that total daily MY in these herds follows expectations of a clearly defined peak for mature cows at wk 8 followed by a steady decline and a flatter lactation curve in first lactation. The lactation curve trends were expected as they have been previously reported in both AMS (Pettersson et al., 2011) and conventional milking systems (Dechow and Goodling, 2008).

\section{Daily Totals}

Descriptive statistics for daily yield totals for Holsteins are reported in Table 2. The average NM was 2.82 corresponding to total MY of $37.94 \mathrm{~kg} / \mathrm{d}$ and 20.43 min of daily MT. Average $305 \mathrm{ME}$ was $11,714 \mathrm{~kg}$, which is very similar to the extrapolation of the total MY of $37.94 \mathrm{~kg} / \mathrm{d}$ to $305 \mathrm{~d}(11,572)$. The NM was toward higher end of a range of 2.36 to 3.05 from other estimates (König et al., 2006; Nixon et al., 2009; Løvendahl and Chagunda, 2011; Castro et al., 2012; Carlström et al., 2013), which corresponds to higher daily MY in the current study. The proportion of cows with at least one KO per day (23.49\%) was high relative to a previous report of $17 \%$ for average daily $\mathrm{KO}$ in Norweigan Red cattle (Wethal and Heringstad, 2019); the reasons for this are not certain and could reflect breed temperament differences or management practices such as the amount of concentrate offered in the AMS. The proportion of IC for individual milkings (5.77\%; Table 1) was similar to the 4.2 to $5.0 \%$ reported by Carlström et al. (2016), and the proportion of cows with at least one IC milking per day (12.51\%) was similar to $12 \%$ average daily IC in Norweigan Red cattle (Wethal and Heringstad, 2019).

\section{Genetic Parameters}

Heritabilities, repeatabilities, genetic, and phenotypic correlations among the AMS traits and 305ME are reported in Table 4. Given the large number of records per cow, repeatability estimates were relatively precise with standard errors of 0.01 whereas standard errors of heritability estimates ranged from 0.01 to 0.06 . Genetic correlation estimates were less precise (average $\mathrm{SE}=$ 0.14) than phenotypic correlations (SE were 0.03 or less); this was expected as the number of records per cow was high relative to the number of cows.

The heritability of $305 \mathrm{ME}$ was 0.30 with a repeatability of 0.48 , which is well within expectation (VanRaden et al., 2009). Daily MY had a low heritability (0.11) and repeatability (0.36) with a genetic correlation with $305 \mathrm{ME}$ of 0.73 . Heritability estimates for first-lactation Holstein cows milked by AMS ranged from 0.14 to 0.20 in Canadian Holsteins (Nixon et al., 2009), from 0.02 


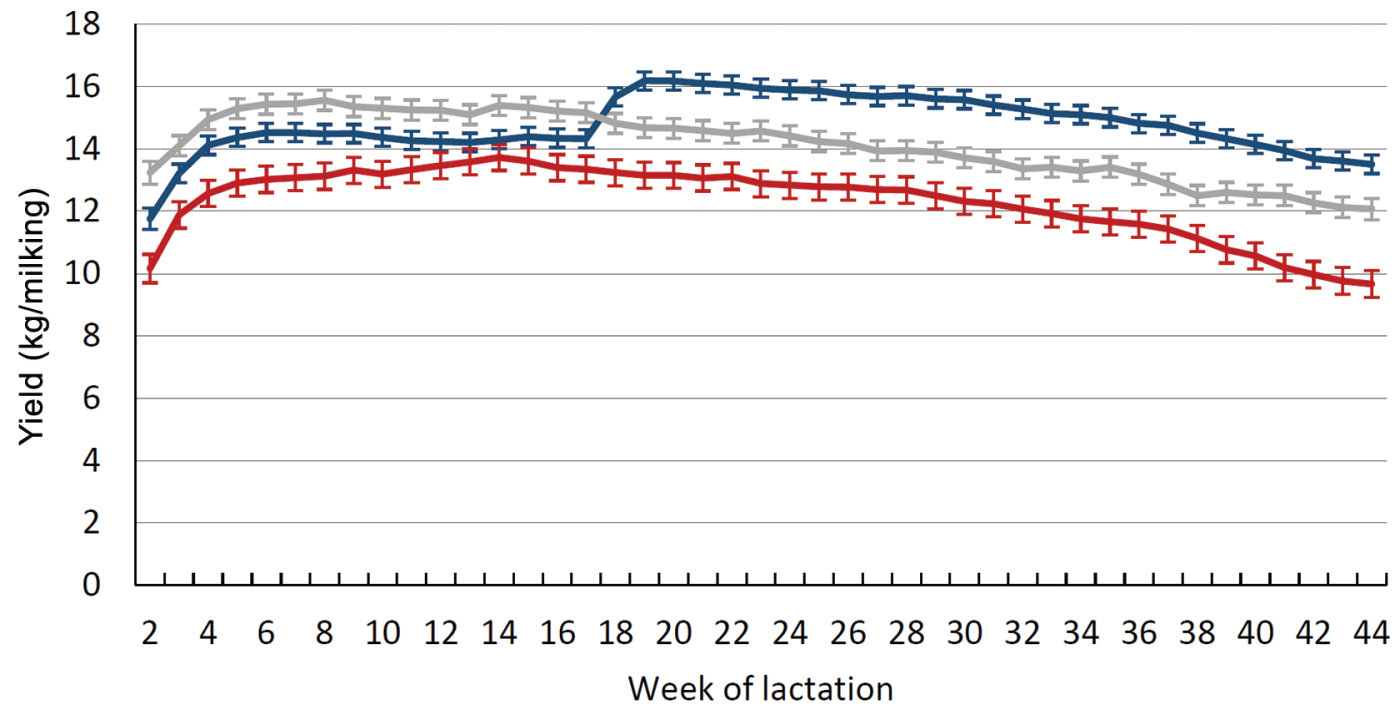

Farm $1 \longrightarrow$ Farm $2=$ Farm 3

Figure 3. Yield $( \pm \mathrm{SE})$ per milking by week of lactation and farm $(1,2$, and 3$)$.

to 0.26 depending on stage of lactation in French Holsteins (Tribout et al., 2018), and from 0.19 to 0.24 for Dutch Holsteins (Mulder et al., 2004). Although our estimate tends to be somewhat lower than those reports, we used data from multiple parities, and it is similar to previous estimates using daily (Toshniwal et al., 2008) or test-day (Sawalha et al., 2005) records from the United States. A random regression model to evaluate change across lactation (Nixon et al., 2009) might have resulted in higher heritability estimates but was beyond the scope of the present study. The genetic correlation estimate between daily MY and 305ME was well below unity; this may partly reflect the fact that most of the 305ME records are from lactations and historic cows not milked by AMS, but is still less than previous genetic correlation estimates ranging from 0.87 to 1.0 between Dutch AMS herds and conventional milking herds from a test-day sire model (Mulder et al., 2004).

The high heritability estimate of FR (0.55) agrees with previous reports ranging from 0.37 to 0.49 for Swedish Holstein, Swedish Red, and Norwegian Red cattle (Carlström et al., 2014; Wethal and Heringstad, 2019). The heritability of HR was moderate (0.30) with strong genetic correlations with FR (0.93) and MT $(-0.84)$. A similar heritability estimate for the ratio of MY to box time (0.22), strong genetic correlation with FR (0.98), and strong genetic correlation with box time $(-0.87)$ was previously reported (Wethal and Heringstad, 2019). Strong genetic correlation estimates between HR and FR are expected given that both are measures of the amount of milk produced in a period of time. Flow rate is a direct measure of how rapidly milk is ejected from the mammary gland whereas HR encompasses FR plus the time required to attach and remove the milking machine. At an equal HR, cows that require minimal time for machine attachment and moderate FR would be preferred to those with longer machine attachment times and high FR; such cows would allow for high AMS efficiency without compromised udder and teat-end health that can be associated with high FR.

Behavior related traits such as KO, IC, and NM all had heritability estimates less than 0.10 using the linear model approach. The heritability estimate for KO was higher when using the threshold model $(0.13 \pm 0.03)$ whereas that of IC $(0.03 \pm 0.01)$ was not; the threshold model estimates provide a more accurate estimate of heritability on the underlying scale, although correlations of true breeding values with EBV estimates from linear or threshold models are expected to be similar (Carlén et al., 2006). Heritability estimates of NM less than 0.10 have been previously reported (Nixon et al., 2009; Carlström et al., 2013; Wethal and Heringstad, 2019), though estimates as high as 0.22 in late lactation were reported for German cattle (König et al., 2006). The genetic correlation estimate between MY and NM was modest (0.26) and lower than previously reported estimates ranging from 0.27 to 0.80 depending on stage of lactation (König et al., 2006; Nixon et al., 2009).

Heritability estimates for IC are generally less than 0.05 (Carlström et al., 2016; Wethal and Heringstad, 2019), and IC appears to be less heritable than KO. 


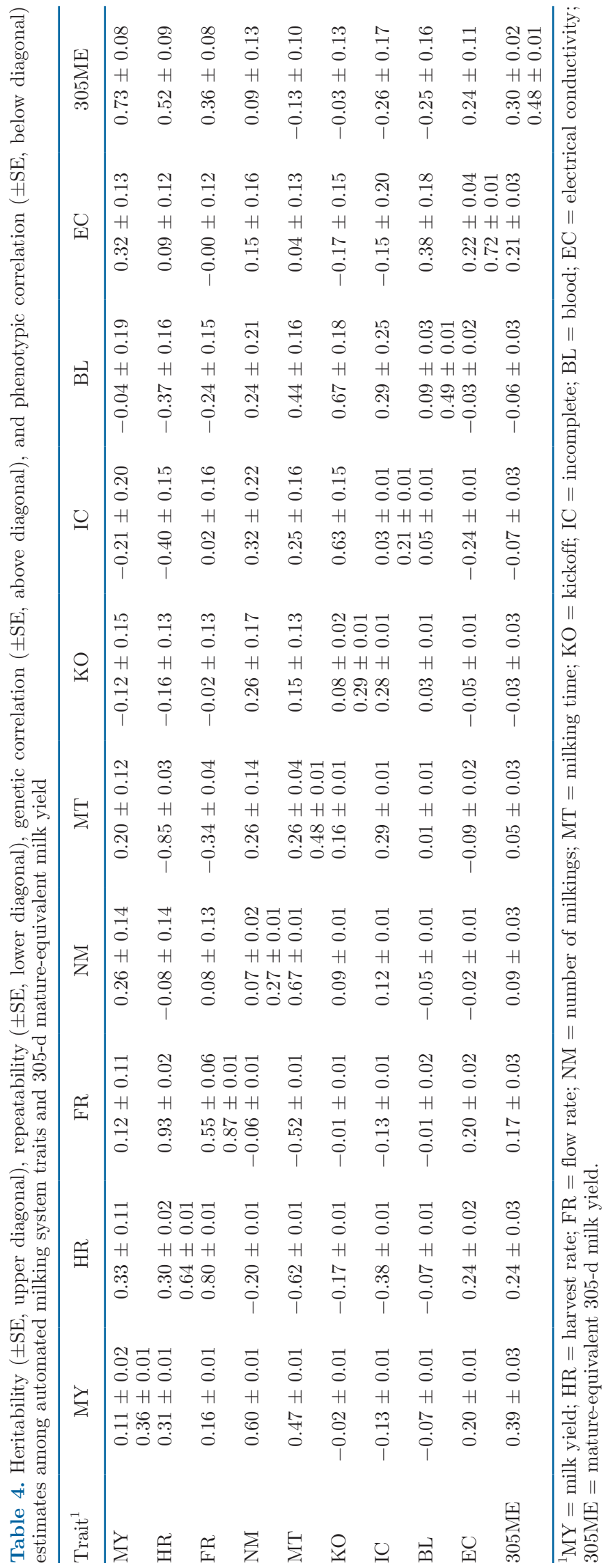

Wethal and Heringstad (2019) estimated heritability for $\mathrm{KO}$ of 0.06 compared with 0.01 for IC. Other authors have included $\mathrm{KO}$ in broader traits such as number of attachments per teat and attachment failures with more moderate heritability estimates of 0.26 (Stephansen et al., 2018) and 0.21 to 0.31 (Carlström et al., 2016), respectively. More KO and IC were genetically and phenotypically associated with reduced HR and longer MT. Similar results have been observed in other studies (Carlström et al., 2016; Wethal and Heringstad, 2019), suggesting that selection to lower their frequency would be advantageous.

\section{Genetic Associations with Other Traits}

Approximate genetic correlations of the AMS traits with udder conformation traits, milk yield, SCS, and mastitis resistance from national genetic evaluations are reported in Table 5 . The correlation between EBV for MY with PTA milk (0.63) was strong, but not as high as might be expected. Whether that is a property of trait definition, farms represented, or evidence of a genotype by environment interaction is uncertain; there was minimal evidence of a genotype by environment interaction between AMS and conventionally milked herds in a previous report (Mulder et al., 2004), suggesting is not likely the sole cause of the lower genetic correlation estimate.

Higher MY was unfavorably correlated with udder health as indicated by SCS and mastitis resistance evaluations. Similarly, faster FR and HR and lower MT were associated with poorer udder health. This relationship has been previously reported (Rupp and Boichard, 1999; Zwald et al., 2005) and highlights the challenge of increasing AMS efficiency without compromising cow health and well-being.

In the absence of genetic evaluations for traits specific to AMS such as HR, KO, IC, and machine handling time, producers rely on udder conformation evaluations to identify sires whose daughters will be well suited for AMS milking. Carlström et al. (2016) previously reported associations of udder conformation traits with milkability traits with many results not consistent between Swedish Holstein and Swedish Red evaluations. For example, a deeper udder cleft was significantly associated with more attachment failures in Holsteins, and significantly associated with fewer attachment failures in Swedish Reds. Closer front and rear teat placement were associated with more IC in Holsteins, but not in Swedish Red. More consistent relationships were reported for udder depth (shallower udders associated with reduced box time) and teat size (longer and thicker teats associated with longer box time). 
Table 5. Approximate genetic correlations of automatic milk system traits with udder conformation traits, milk yield, somatic cell score, and mastitis resistance based on genetic evaluations for 214 Holstein sires with reliability for MY of $25 \%$ or greater

\begin{tabular}{|c|c|c|c|c|c|c|c|c|c|}
\hline Trait $^{1}$ & Milk & SCS & $\begin{array}{l}\text { Mastitis } \\
\text { resistance }\end{array}$ & $\begin{array}{c}\text { Udder } \\
\text { composite }\end{array}$ & $\begin{array}{l}\text { Udder } \\
\text { depth }\end{array}$ & $\begin{array}{l}\text { Rear teat } \\
\text { placement }\end{array}$ & $\begin{array}{c}\text { Teat } \\
\text { length }\end{array}$ & $\begin{array}{l}\text { Rear udder } \\
\text { height }\end{array}$ & Fat $\%$ \\
\hline MY & $0.63^{* * *}$ & $0.38^{* *}$ & $-0.30 * *$ & -0.08 & $-0.30 * *$ & 0.01 & 0.09 & 0.03 & $-0.43^{* * *}$ \\
\hline NM & -0.02 & -0.04 & 0.12 & $0.23 \dagger$ & 0.14 & 0.00 & -0.15 & 0.20 & -0.09 \\
\hline MT & 0.07 & $-0.25^{*}$ & $0.19 \dagger$ & 0.17 & -0.08 & 0.09 & -0.02 & $0.24^{*}$ & 0.05 \\
\hline $\mathrm{KO}$ & -0.04 & 0.04 & -0.05 & 0.00 & -0.12 & 0.03 & $-0.34^{* *}$ & 0.02 & -0.05 \\
\hline $\mathrm{EC}$ & $0.54^{* * *}$ & 0.02 & 0.01 & $0.30^{*}$ & 0.10 & 0.12 & -0.17 & $0.35^{* *}$ & $-0.39^{* *}$ \\
\hline
\end{tabular}

${ }^{1} \mathrm{MY}=$ milk yield $\mathrm{HR}=$ harvest rate; $\mathrm{FR}=$ flow rate; $\mathrm{NM}=$ number of milkings; $\mathrm{MT}=$ milking time; $\mathrm{KO}=$ kickoff; $\mathrm{IC}=$ incomplete; $\mathrm{BL}=$ blood; $\mathrm{EC}=$ electrical conductivity.

*** $P<0.001 ; * * P<0.01 ;{ }^{*} P<0.05 ; \dagger P<0.10$.

In the present study (Table 5), most udder conformation traits had weak relationships to measures of milkability. Higher rear udder attachments were unfavorably associated with HR, and there was a tendency toward an unfavorable association of $\mathrm{HR}$ with udder composite. The strongest genetic correlation estimates were for teat length, with longer teats associated with a favorable reduction in $\mathrm{KO}$ and IC. Longer teats were also associated with a reduction in attachment failures in Swedish Red cattle, but not in Swedish Holsteins (Carlström et al., 2016).

Differences among Holsteins from the present study, Swedish Holsteins, and Swedish Reds may reflect differences in the typical udder conformation of the different breeds. Teat placement was closer and udder clefts deeper in Swedish Holsteins than in Swedish Reds, whereas teat length was shorter in Swedish Reds (Carlström et al., 2016). This suggests that relationships of milkability with udder traits may not be consistent across breeds, populations, and time.

Previous studies support the use of EC as a phenotypic (Norberg et al., 2004a) and genetic indicator (Norberg et al., 2004b) of mastitis. However, we were unable to replicate that result with associations with SCS and mastitis resistance near zero. We also explored alternate EC measures such as the frequency in spikes of EC and inter-quarter EC ratios, but they were not associated with SCS or mastitis resistance (approximate genetic correlations ranged from -0.11 to 0.05 ) so were not explored further. We were also unable to establish a relationship between BL and udder health traits; higher BL was associated with higher fat concentration, which corresponds to communications with farm personnel that BL warning were more likely for cows with high milk fat. There was a strong association of BL and stage of lactation (Supplemental Figure S7, https://doi.org/10.3168/jds.2020-18786) with high BL in early lactation. False positives when milk takes on a yellow color are common (Hovinen and Pyörälä, 2011), which may explain the genetic correlation of BL with milk fat concentration in the present study.

Increasing HR facilitates more milk harvested from the AMS in a given time period, which is a primary consideration for decreasing the time required to recoup investments in AMS (Castro et al., 2012); unfortunately, HR was unfavorably associated with udder health. Selection for reduced machine handling time might facilitate an increase in the amount of milk produced in a time period without increasing the risk of mastitis. Direct computation of handling time requires box entry and exit times, which were not available to us; instead we explored partial correlations of HR with nationally evaluated traits after adjustment for FR. Results are presented in Table 6 along with the original correlations for comparison. Partial correlations with SCS and mastitis resistance were near zero, suggesting that factors which increase HR without increasing FR are promising opportunities to increase AMS efficiency. Udder depth and udder composite had unfavorable partial correlations, likely due to negative correlations with MY. The association of TL and HR was favorable after considering FR, which reflects lower $\mathrm{KO}$ and IC

Table 6. Correlations $\left(\mathrm{r}_{\mathrm{XY}}\right)$ of milk harvest rate with udder conformation traits, milk yield, SCS, and mastitis resistance and partial correlations after adjustment for milk flow rate $\left(\mathrm{r}_{\mathrm{XY} \mid \mathrm{FR}}\right)$

\begin{tabular}{lcc}
\hline Trait & $\mathrm{r}_{\mathrm{XY}}$ & $\mathrm{r}_{\mathrm{XY} \mid \mathrm{FR}}$ \\
\hline Milk & $0.13 \dagger$ & $0.20^{* *}$ \\
SCS & $0.26^{* * *}$ & 0.03 \\
Mastitis resistance & $-0.18^{* *}$ & -0.02 \\
Udder composite & $-0.13 \dagger$ & $-0.17^{*}$ \\
Udder depth & -0.04 & $-0.15^{*}$ \\
Rear teat placement & -0.06 & -0.09 \\
Teat length & 0.03 & $0.22^{*}$ \\
Rear udder height & $-0.15^{*}$ & $-0.12 \dagger$ \\
Fat \% & $-0.17^{*}$ & $-0.13 \dagger$ \\
\hline
\end{tabular}

*** $P<0.001 ;{ }^{* *} P<0.01 ; * P<0.05 ; \dagger P<0.10$. 
with longer teats and lower FR associated with longer teats (Zwald et al., 2005).

The DDW was able to provide data to facilitate genetic research. However, some important information that would be valuable for genetic evaluation such as box entry and exit times was not captured indicating that closer collaboration of researchers with the service provider is required. Services such as DDW should be considered for providing data that does not easily flow through traditional milk recording systems and not as a replacement for traditionally evaluated traits such as SCS.

\section{CONCLUSIONS}

There are genetic differences among Holsteins for milking efficiency and behavioral traits, suggesting selection for cows that will enhance efficiency in AMS systems is possible. Such selection would consider faster machine attachment, fewer milkings that are incomplete or interrupted by a machine kicked off, and milking speed optimized to increase the amount of milk harvested per day without compromising udder health; the unfavorable association of milking speed with udder health traits calls for focus on traits that increase milk harvested per day that are independent of milk flow rate. Genetic associations with udder conformation suggested that selection for higher udder composite will not improve milking efficiency. This suggests direct selection of traits related to AMS efficiency would be advantageous. Cloud-based data capture and storage through DDW or similar services could facilitate such selection, but will require close coordination with geneticists to ensure that data of sufficient depth and quality is collected.

\section{ACKNOWLEDGMENTS}

This project would not have been possible without data sharing by the cooperating farms. Appreciation is expressed to the Data Dairy Warehouse for providing a data access mechanism. This work was supported by the USDA National Institute of Food and Agriculture and Hatch Appropriations under Project \#PEN04691 and Accession \#1018545. The authors have not stated any conflicts of interest.

\section{REFERENCES}

Árnason, T., E. Albertsdóttir, W. F. Fikse, S. Eriksson, and Á. Sigurdsson. 2012. Estimation of genetic parameters and response to selection for a continuous trait subject to culling before testing. J. Anim. Breed. Genet. 129:50-59. https://doi.org/10.1111/j.1439 -0388.2011.00941.x.
Calo, L. L., R. E. McDowell, L. D. VanVleck, and P. D. Miller. 1973. Genetic aspects of beef production among Holstein-Friesians pedigree selected for milk production. J. Anim. Sci. 37:676-682. https: //doi.org/10.2527/jas1973.373676x.

Carlén, E., U. Emanuelson, and E. Strandberg. 2006. Genetic evaluation of mastitis in dairy cattle using linear models, threshold models, and survival analysis: A simulation study. J. Dairy Sci. 89:4049-4057. https://doi.org/10.3168/jds.S0022-0302(06)72448 $-1$.

Carlström, C., G. Pettersson, K. Johansson, E. Strandberg, H. Stålhammar, and J. Philipsson. 2013. Feasibility of using automatic milking system data from commercial herds for genetic analysis of milkability. J. Dairy Sci. 96:5324-5332. https://doi.org/10.3168/ jds.2012-6221.

Carlström, C., E. Strandberg, K. Johansson, G. Pettersson, H. Stålhammar, and J. Philipsson. 2014. Genetic evaluation of in-line recorded milkability from milking parlors and automatic milking systems. J. Dairy Sci. 97:497-506. https://doi.org/10.3168/jds .2013-6948.

Carlström, C., E. Strandberg, G. Pettersson, K. Johansson, H. Stålhammar, and J. Philipsson. 2016. Genetic associations of teat cup attachment failures, incomplete milkings, and handling time in automatic milking systems with milkability, temperament, and udder conformation. Acta Agric. Scand. Sect. Anim. Sci. 66:75-83. https: //doi.org/10.1080/09064702.2016.1260153.

Castro, A., J. M. Pereira, C. Amiama, and J. Bueno. 2012. Estimating efficiency in automatic milking systems. J. Dairy Sci. 95:929-936. https://doi.org/10.3168/jds.2010-3912.

Dechow, C. D., and R. C. Goodling. 2008. Mortality, culling by sixty days in milk, and production profiles in high- and low-survival Pennsylvania herds. J. Dairy Sci. 91:4630-4639. https://doi.org/ 10.3168/jds.2008-1337.

Gilmour, A. R., B. J. Gogel, B. R. Cullis, S. J. Welham, and R. Thompson. 2014. ASReml User Guide Release 4.1 Functional Specification. VSN Int. Ltd., Hemel Hempstead, UK. www.vsni .co.uk.

Hovinen, M., A.-M. Aisla, and S. Pyörälä. 2006. Accuracy and reliability of mastitis detection with electrical conductivity and milk colour measurement in automatic milking. Acta Agric. Scand. Sect. Anim. Sci. 56:121-127. https://doi.org/10.1080/ 09064700701216888.

Hovinen, M., and S. Pyörälä. 2011. Invited review: Udder health of dairy cows in automatic milking. J. Dairy Sci. 94:547-562. https:/ /doi.org/10.3168/jds.2010-3556.

Khatun, M., R. M. Bruckmaier, P. C. Thomson, J. House, and S. C. García. 2019. Suitability of somatic cell count, electrical conductivity, and lactate dehydrogenase activity in foremilk before versus after alveolar milk ejection for mastitis detection. J. Dairy Sci. 102:9200-9212. https://doi.org/10.3168/jds.2018-15752.

Khatun, M., P. C. Thomson, K. L. Kerrisk, N. A. Lyons, C. E. F. Clark, J. Molfino, and S. C. García. 2018. Development of a new clinical mastitis detection method for automatic milking systems. J. Dairy Sci. 101:9385-9395. https://doi.org/10.3168/jds.2017 $-14310$.

König, S., F. Köhn, K. Kuwan, H. Simianer, and M. Gauly. 2006. Use of repeated measures analysis for evaluation of genetic background of dairy cattle behavior in automatic milking systems. J. Dairy Sci. 89:3636-3644. https://doi.org/10.3168/jds.S0022-0302(06)72403 $-1$.

Løvendahl, P., and M. G. G. Chagunda. 2011. Covariance among milking frequency, milk yield, and milk composition from automatically milked cows. J. Dairy Sci. 94:5381-5392. https://doi.org/10 .3168/jds.2010-3589.

Mathijs, E. 2004. Summary for Policymakers. Intergovernmental Panel on Climate Change, ed. Cambridge University Press, Cambridge, UK.

Miglior, F., A. Sewalem, J. Jamrozik, J. Bohmanova, D. M. Lefebvre, and R. K. Moore. 2007. Genetic analysis of milk urea nitrogen and lactose and their relationships with other production traits in Canadian Holstein cattle. J. Dairy Sci. 90:2468-2479. https://doi .org/10.3168/jds.2006-487. 
Moyes, K. M., L. Ma, T. K. McCoy, and R. R. Peters. 2014. A survey regarding the interest and concern associated with transitioning from conventional to automated (robotic) milking systems for managers of small-to medium-sized dairy farms. Appl. Anim. Sci. 30:418-422. https://doi.org/10.15232/pas.2014-01327.

Mulder, H. A., A. F. Groen, G. De Jong, and P. Bijma. 2004. Genotype $\times$ environment interaction for yield and somatic cell score with automatic and conventional milking systems. J. Dairy Sci. 87:1487-1495. https://doi.org/10.3168/jds.S0022-0302(04)73300 -7 .

Nixon, M., J. Bohmanova, J. Jamrozik, L. R. Schaeffer, K. Hand, and F. Miglior. 2009. Genetic parameters of milking frequency and milk production traits in Canadian Holsteins milked by an automated milking system. J. Dairy Sci. 92:3422-3430. https://doi .org/10.3168/jds.2008-1689.

Norberg, E., H. Hogeveen, I. R. Korsgaard, N. C. Friggens, K. H. M. N. Sloth, and P. Løvendahl. 2004a. Electrical conductivity of milk: Ability to predict mastitis status. J. Dairy Sci. 87:1099-1107. https://doi.org/10.3168/jds.S0022-0302(04)73256-7.

Norberg, E., G. W. Rogers, R. C. Goodling, J. B. Cooper, and P. Madsen. 2004b. Genetic parameters for test-day electrical conductivity of milk for first-lactation cows from random regression models. J. Dairy Sci. 87:1917-1924. https://doi.org/10.3168/jds.S0022 -0302(04)73350-0.

Pantoja, J. C. F., A. P. Almeida, B. dos Santos, and R. S. Rossi. 2016. An investigation of risk factors for two successive cases of clinical mastitis in the same lactation. Livest. Sci. 194:10-16. https://doi .org/10.1016/j.livsci.2016.10.010.

Pettersson, G., K. Svennersten-Sjaunja, and C. H. Knight. 2011. Relationships between milking frequency, lactation persistency and milk yield in Swedish Red heifers and cows milked in a voluntary attendance automatic milking system. J. Dairy Res. 78:379-384. https://doi.org/10.1017/S0022029911000471.

Pollak, E. J., J. van der Werf, and R. L. Quaas. 1984. Selection bias and multiple trait evaluation. J. Dairy Sci. 67:1590-1595. https:// doi.org/10.3168/jds.S0022-0302(84)81481-2.

Poppe, M., H. A. Mulder, B. J. Ducro, and G. de Jong. 2019. Genetic analysis of udder conformation traits derived from automatic milking system recording in dairy cows. J. Dairy Sci. 102:1386-1396. https://doi.org/10.3168/jds.2018-14838.

Rodenburg, J. 2017. Robotic milking: Technology, farm design, and effects on work flow. J. Dairy Sci. 100:7729-7738. https://doi.org/ $10.3168 /$ jds.2016-11715.

Rupp, R., and D. Boichard. 1999. Genetic parameters for clinical mastitis, somatic cell score, production, udder type traits, and milking ease in first lactation Holsteins. J. Dairy Sci. 82:2198-2204. https: //doi.org/10.3168/jds.S0022-0302(99)75465-2.

Safayi, S., P. K. Theil, V. S. Elbrønd, L. Hou, M. Engbæk, J. V. Nørgaard, K. Sejrsen, and M. O. Nielsen. 2010. Mammary remodeling in primiparous and multiparous dairy goats during lactation. J. Dairy Sci. 93:1478-1490. https://doi.org/10.3168/jds.2009-2422.

Salfer, J. A., K. Minegishi, W. Lazarus, E. Berning, and M. I. Endres. 2017. Finances and returns for robotic dairies. J. Dairy Sci. 100:7739-7749. https://doi.org/10.3168/jds.2016-11976.
Sawalha, R. M., J. F. Keown, S. D. Kachman, and L. D. Van Vleck. 2005. Evaluation of autoregressive covariance structures for testday records of Holstein cows: Estimates of parameters. J. Dairy Sci. 88:2632-2642. https://doi.org/10.3168/jds.S0022-0302(05)72940 -4 .

Stephansen, R. S., A. Fogh, and E. Norberg. 2018. Genetic parameters for handling and milking temperament in Danish first-parity Holstein cows. J. Dairy Sci. 101:11033-11039. https://doi.org/10 $.3168 /$ jds.2018-14804.

Toshniwal, J. K., C. D. Dechow, B. G. Cassell, J. A. D. R. N. Appuhamy, and G. A. Varga. 2008. Heritability of electronically recorded daily body weight and correlations with yield, dry matter intake, and body condition score. J. Dairy Sci. 91:3201-3210. https://doi.org/10.3168/jds.2007-0627.

Tribout, T., S. Minery, B. Dassé, D. Saunier, V. Ducrocq, and D. Boichard. 2018. Joint estimation of genetic parameters for daily recorded milk yield and body weight in first lactation Holstein cows. Page 489 in Proceedings of the World Congress on Genetics Applied to Livestock Production, Auckland, New Zealand. World Congress on Genetics Applied to Livestock Production Digital Archives. Accessed Sep. 10, 2020. http://www.wcgalp.org/ proceedings $/ 2018$.

VanRaden, P. M., C. P. Van Tassell, G. R. Wiggans, T. S. Sonstegard, R. D. Schnabel, J. F. Taylor, and F. S. Schenkel. 2009. Invited review: Reliability of genomic predictions for North American Holstein bulls. J. Dairy Sci. 92:16-24. https://doi.org/10.3168/jds .2008-1514.

Wethal, K. B., and B. Heringstad. 2019. Genetic analyses of novel temperament and milkability traits in Norwegian Red cattle based on data from automatic milking systems. J. Dairy Sci. 102:8221-8233. https://doi.org/10.3168/jds.2019-16625.

Wethal, K. B., M. Svendsen, and B. Heringstad. 2020. Are farmer assessed temperament, milking speed, and leakage genetically the same traits in automatic milking systems and traditional milking systems? J. Dairy Sci. 103:3325-3333. https://doi.org/10.3168/jds .2019-17503.

Zwald, N. R., K. A. Weigel, Y. M. Chang, R. D. Welper, and J. S. Clay. 2005. Genetic evaluation of dairy sires for milking duration using electronically recorded milking times of their daughters. J. Dairy Sci. 88:1192-1198. https://doi.org/10.3168/jds.S0022 -0302(05)72785-5.

\section{ORCIDS}

C. D. Dechow (ํ) https://orcid.org/0000-0002-9012-2807

K. S. Sondericker () https://orcid.org/0000-0003-4701-5480

A. A. Enab ® https://orcid.org/0000-0003-2902-7816

L. C. Hardie @ https://orcid.org/0000-0001-9869-3447 